\title{
Sexually transmitted diseases in homosexual men: A study of four societies
}

\author{
MICHAEL W ROSS
}

From the Department of Psychiatry, Flinders University of South Australia, Bedford Park, South Australia, Australia

SUMMARY The prevalence of venereal disease among homosexual men was investigated by looking at non-clinic patients from Sweden, Australia, Finland, and the Republic of Ireland. Results showed significant differences between nationalities in the incidence of syphilis, gonorrhoea, other sexually transmitted diseases (STD), number of variables of presentation to STD clinics, and number of infections. Data were interpreted as indicating that social and cultural factors may influence incidence of STD in male homosexuals.

\section{Introduction}

Most information regarding the incidence and prevalence of sexually transmitted diseases (STD) in homosexual men has relied upon those who have presented to STD clinics, and there is very little information on homosexuals not attending clinics. Only two studies have investigated the prevalence of homosexually acquired STD in sexually active homosexuals in any detail; those of Darrow et al in the United States, ${ }^{\prime}$ and Ross in Sweden and Australia. $^{2}$

Darrow et al undertook a survey of 4212 homosexual men by questionnaire (in which only four of 692 questions related to STD) distributed in a gay magazine. While Handsfield has noted that this represents a response rate of only $1.5 \%,{ }^{3}$ Darrow's research demonstrated that $78 \%$ of respondents had experienced at least one episode of STD $(60 \%$ excluding pediculosis), and that only $36 \%$ had attended public clinics. Similarly, Ross looking at 157 Australian and 176 Swedish homosexual men and using a questionnaire which contained questions relating to STD as part of a major study of homosexual lifestyles found that $29.9 \%$ of Australians and $38.6 \%$ of Swedes had had gonorrhoea, and $8 \cdot 3 \%$ and $13 \cdot 1 \%$ respectively had had syphilis. ${ }^{2}$ Ross noted that there were some appreciable differences between the two cultures in acceptance of homosexual behaviour. He also noted that, as those surveyed were the most likely to have a large number of partners and probably constituted less than $1 \%$ of

Address for reprints: Dr Michael Ross, Department of Psychiatry, Flinders University Medical School, Bedford Park, SA 5042, Australia

Accepted for publication 18 July 1983 the homosexual population in the cities where they were studied, the figures should be seen in context and not generalised to all male homosexuals. Handsfield makes similar observations regarding generalisation from the data of Darrow et al. It is of note, however, that Darrow's figures for the United States and Ross's figures for Sweden are very similar (gonorrhoea 38.4 v38.6\%, syphilis 13.5 v13.1\%). Bell and Weinberg also noted that over two thirds of the homosexual men they studied in the United States in the early 1970 's had had STD. ${ }^{4}$

These similarities raise a number of questions. First, to what degree are these figures representative of other Western societies? Second, as a corollary to this, do social factors play a part in incidence of different STDs? This study attempted to answer these questions by looking at two further countries (Finland and Ireland) in addition to the two (Sweden and Australia) investigated by Ross in 1982.

\section{Subjects and methods}

The subjects and methods followed the format of those reported by Ross, ${ }^{2}$ with the addition of two further groups: homosexual men from Finland and the Irish Republic.

\section{STUDY POPULATION}

The study population consisted of 176 Swedish, 158 Australian, 149 Finnish, and 121 Irish homosexual men (604 respondents in total), whose characteristics are given in Table $I$.

Questionnaires with stamped addressed envelopes for return were given to homosexual rights and social clubs in Stockholm, Melbourne and Brisbane, Helsinki, and Dublin. In each case the club was the 
TABLE I Mean (SD) characteristics of homosexuals in four countries

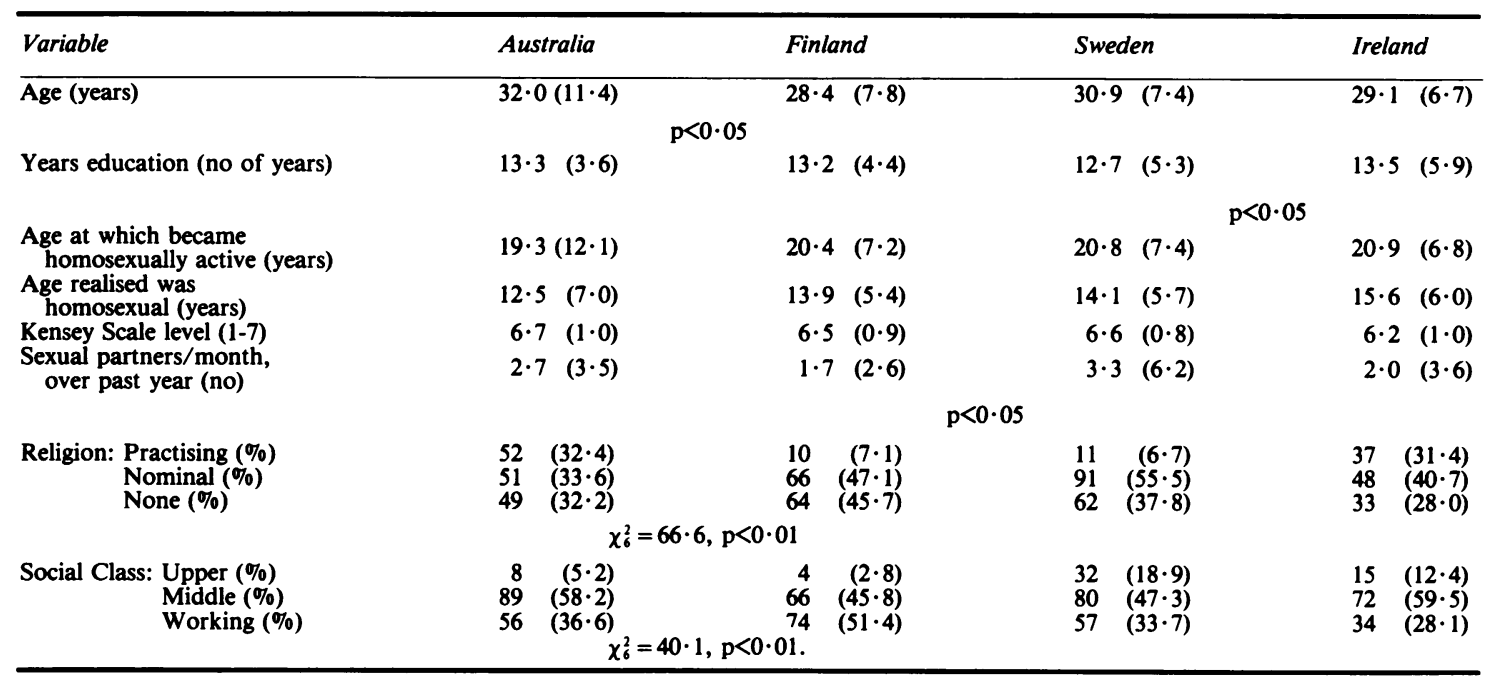

main homosexual rights or social organisation in that city, and the aims and functions of the five clubs selected appeared to be almost identical. The response rate was $46.6 \%$ for Stockholm, $44 \%$ for Melbourne and Brisbane, $54 \%$ for Helsinki, and $48.6 \%$ for Dublin. This response rate was based on the number of questionnaires given to each club, one for each member on its mailing list.

\section{QUESTIONNAIRE}

The questions asked were part of an anonymous wider questionnaire comparing homosexual men in Sweden, Australia, Finland, and Ireland. Respondents were asked whether they had had gonorrhoea, syphilis, or any other STD (they were asked to state which), and the number of times they had had each. Further questions, replies to which were yes or no, asked whether the respondent had visited a public clinic or local medical practitioner on the last occasion they contracted STD, whether they had admitted the source of infection was homosexual, whether they had had any adverse experiences in a public clinic, whether they went to a particular clinic in preference to any other, and whether (on up to five possible occasions) they knew the person by whom they had been infected or knew any details which would make it possible to trace sexual contacts for up to five possible occasions. Finally, they were asked the average number of different partners they had had each month over the past year. Ten questionnaires from each sample in which respondents identified themselves were subsequently compared with interviews with the men as a check on accuracy, and no discrepancies were found. Swedish questionnaires were translated into Swedish by two people and checked for accuracy by a third; translation of the Finnish questionnaire followed a similar procedure. Questionnaires in Australia and Ireland were in English.

DATA ANALYSIS

Analyis was by the $\chi^{2}$ test for the categorical data and by Student's $t$ test for the data which had interval or ratio scales. $\chi^{2}$ results were calculated on absolute numbers in all cases, but in some tables raw percentages are given to enable clearer comparisons between countries. Differences between samples were tested by one way analysis of variance using post hoc Scheffé tests to determine where any difference existed.

\section{Results}

Results are presented in tables II to IV. Some differences were apparent between the study populations (see Table I). One way analysis of variance showed that there were significant differences

TABLE II Percentage prevalence of STD in homosexuals in four countries

\begin{tabular}{|c|c|c|c|}
\hline Infection & Sweden & Australia & Ireland \\
\hline Gonorrhoea & $38 \cdot 6$ & $\begin{array}{cc}31 \cdot 0 & 22 \cdot 2 \\
\chi_{3}^{2}=14 \cdot 6, p<0 \cdot 01\end{array}$ & $19 \cdot 8$ \\
\hline Syphilis & $13 \cdot 1$ & $\begin{array}{l}8 \cdot 2 \\
\chi_{3}^{2}=9 \cdot 3, p<0.05\end{array}$ & $5 \cdot 0$ \\
\hline Other STD & $14 \cdot 8$ & $\begin{array}{l}19 \cdot 6 \\
\chi_{3}^{2}=15 \cdot 0, p<0 \cdot 01\end{array}$ & $19 \cdot 0$ \\
\hline
\end{tabular}


TABLE III No (\%) homosexuals infected with STD in four countries

\begin{tabular}{lcccc}
\hline $\begin{array}{l}\text { No of times } \\
\text { infected }\end{array}$ & $\begin{array}{l}\text { Sweden } \\
(n=176)\end{array}$ & $\begin{array}{c}\text { Australia } \\
(n=158)\end{array}$ & $\begin{array}{l}\text { Finland } \\
(n=149)\end{array}$ & $\begin{array}{l}\text { Ireland } \\
(n=121)\end{array}$ \\
\hline Never & $91(52 \cdot 3)$ & $100(63 \cdot 3)$ & $99(67 \cdot 3)$ & $83(68 \cdot 0)$ \\
1 & $29(16 \cdot 5)$ & $19(12 \cdot 0)$ & $34(23 \cdot 1)$ & $15(12 \cdot 3)$ \\
2 & $25(14 \cdot 2)$ & $19(12 \cdot 0)$ & $4(2 \cdot 7)$ & $13(10 \cdot 7)$ \\
3 & $12(6 \cdot 8)$ & $5(3 \cdot 2)$ & $3(2 \cdot 0)$ & $2(1 \cdot 6)$ \\
4 & $6(3 \cdot 4)$ & $8(5 \cdot 1)$ & $5(3 \cdot 4)$ & $3(1 \cdot 6)$ \\
5 & $3(1 \cdot 7)$ & 1 & $3 \cdot 6)$ & $5(3 \cdot 5)$ \\
6 or more & $10(5 \cdot 7)$ & $6(3 \cdot 8)$ & $2(1 \cdot 4)$ & $4(3 \cdot 3)$ \\
$\begin{array}{l}\text { Mean no of } \\
\text { infections }\end{array}$ & $2 \cdot 84$ & $1 \cdot 91$ & $1 \cdot 83$ & $2 \cdot 49$ \\
\hline
\end{tabular}

between Australia and Finland in ages of the respondents (3.6 years on average), in years of education between Sweden and Ireland $(0 \cdot 8$ years on average), and in number of sexual partners per month over the past year between Sweden and Finland (1.6 per month on average). There were also significant differences between the four countries in terms of the social class of respondents, with more Swedes and Irishmen reporting that their parents were upper class, and in terms of religious involvement, with more Australians and Irishmen reporting that they were practising members of religions.

The data in Tables II to IV indicate that there are significant differences between countries for prevalence of all STD studied: gonorrhoea, syphilis, and other infections (primarily non-gonococcal urethritis). Of those infected with any STD, the number of infections also differed between countries, and this pattern was repeated for all the variables in Table IV (place of attendance, admitting that the source of infection was homosexual, and choosing a particular clinic) with the exception of negative experiences in a public clinic.

\section{Discussion}

It is difficult to see how any of the differences between the study populations might affect results.
The differences in social class are not parallelled by educational differences, and the age differences are minimal, with only three and a half years difference between the highest and the lowest mean figures. There were no differences between countries in the ages when respondents realised they were homosexual, or those at which they became homosexually active. Of more importance are the differences between study populations in average numbers of partners per month, which may affect findings. However, it is not possible to tie the number of partners over the past year to numbers over a lifetime, so the effect of this difference on the data is not clear. The difference on the variable of religion is accounted for in Australia by large congregations of the Metropolitan Community Church, which has a predominantly homosexual congregation. In Ireland, the result is probably due to the influence of the Roman Catholic Church, an organisation which is more closely identified with nationalism than are churches in any of the other three countries studied. Hart, however, has noted that there is no convincing relation between religions and STD. ${ }^{5}$ These differences between study populations should not affect results, as they are essentially random in distribution. Given the substantial similarities between them, however, and the large number of subjects, these data suggest that the four study populations are reasonably well matched.

The hypothesis that infection rates in homosexual men are affected by cultural variables is supported by the evidence in Table II, which indicates that both syphilis and gonorrhoea follow the same pattern, with the highest prevalence in Sweden and the lowest in Ireland. Other STD infections, however, show a different pattern with the lowest prevalence in the two Scandinavian countries and the highest in Australia and Ireland (the two more anti homosexual societies). Similarly, Table III demonstrates cultural differences, with the rates of reinfection being higher

TABLE IV Percentage differences in presentation in four countries

\begin{tabular}{|c|c|c|c|c|c|}
\hline & & Sweden & Australia & Finland & Ireland \\
\hline $\begin{array}{l}\text { Went to public clinic or } \\
\text { private practitioner }\end{array}$ & $\begin{array}{l}\text { Clinic } \\
\text { Private }\end{array}$ & $\begin{array}{l}80 \cdot 2 \\
19 \cdot 8\end{array}$ & $\begin{array}{l}40 \cdot 0 \\
60 \cdot 0 \\
\chi_{3}^{2}=26\end{array}$ & $\begin{array}{l}76 \cdot 2 \\
23 \cdot 8 \\
01\end{array}$ & $\begin{array}{l}64 \cdot 9 \\
35 \cdot 1\end{array}$ \\
\hline $\begin{array}{l}\text { Admitted source of } \\
\text { infection homosexual? }\end{array}$ & $\begin{array}{l}\text { Yes } \\
\text { No }\end{array}$ & $\begin{array}{l}79 \cdot 5 \\
20 \cdot 5\end{array}$ & $\begin{array}{l}78 \cdot 9 \\
21 \cdot 1 \\
\chi_{3}^{2}=21\end{array}$ & $\begin{array}{l}47 \cdot 7 \\
52 \cdot 3 \\
01\end{array}$ & $\begin{array}{l}77 \cdot 8 \\
22 \cdot 2\end{array}$ \\
\hline $\begin{array}{l}\text { Negative experiences } \\
\text { in public clinic }\end{array}$ & $\begin{array}{l}\text { Yes } \\
\text { No }\end{array}$ & \multicolumn{4}{|c|}{$\chi_{3}^{2}=0 \cdot 60, \mathrm{NS}$} \\
\hline $\begin{array}{l}\text { Went to a particular } \\
\text { public clinic }\end{array}$ & $\begin{array}{l}\text { Yes } \\
\text { No }\end{array}$ & $\begin{array}{l}28 \cdot 1 \\
71 \cdot 9\end{array}$ & $\begin{array}{l}49 \cdot 0 \\
51 \cdot 0 \\
\chi_{3}^{2}=8\end{array}$ & $\begin{array}{l}47 \cdot 2 \\
52 \cdot 8 \\
5\end{array}$ & $\begin{array}{l}54 \cdot 5 \\
45 \cdot 5\end{array}$ \\
\hline
\end{tabular}


in the two more industrialised nations, Sweden and Australia, and lower in the two more agrarian and smaller ones (Ireland and Finland).

Differences between countries also occurred in presentation (Table IV), although the significant differences in proportions presenting to public STD clinics as opposed to private practitioners may to some degree be a reflection of the limited private sector practice in Sweden. Australia was the only country where a majority of respondents attended private practitioners. Perhaps more important, there were also significant differences between countries in terms of the numbers of men who admitted that the source of infection was homosexual. Of particular concern must be the Finnish figures indicating that less than half admitted to homosexual contact. That this may be related to attitudes toward homosexuality in Finland is indicated by previous research by Suhonen $e t$ al, which noted that major changes in the reporting of homosexual contact in syphilis occurred after homosexual law reform in 1971 and then notably decreased. ${ }^{6}$ It is possible that the Finnish figures reflect more negative teaching regarding homosexuality in Finnish medical schools until recently than in the other three countries, which may lead to far lower disclosure. There were no significant differences, however, in negative experiences in public clinics, although Finland did have the highest proportion in this respect. There were minor differences in preferences for particular clinics, although these data must be interpreted with caution as, in some places, there may have been little or no choice available. They do indicate that homosexual men will attend some clinics, where presumably the staff are more accepting or friendly, in preference to others.

In terms of theory, these data do confirm the two hypotheses postulated: first, that there are variations in the prevalence of STD in different countries and, as a consequence of this, that cultural factors play a part in the patterns of STD infections, at least in homosexual men. The factors that actually influence variation between cultures probably include the size of the country, the degree of industrialisation, and possibly attitudes toward sexuality and homosexuality. Second, these data confirm that while there are some similarities between the figures obtained by Darrow et al for the United States and the Swedish data, figures for other countries are much lower. Data from the United States thus tend to overestimate the problem, probably as a reflection of size and degree of development of the society. High rates of STD in homosexuals are thus clearly not a result of homosexual orientation in itself, but response to cultural and social influences.

Clearly, further research is needed to establish the social and psychological variables involved in STD in homosexual men. Nevertheless, it is clear that such factors do influence both the prevalence, and presentation, of homosexually acquired STD.

\section{References}

1. Darrow WW, Barrett MS, Jay K, Young A. The gay report on sexually transmitted diseases. Am $J$ Public Health 1981;71: 1004-11.

2. Ross MW. Social factors in homosexually acquired venereal disease: a comparison between Sweden and Australia. $\mathrm{Br} J$ Vener Dis 1982;58:263-8.

3. Handsfield $\mathbf{H H}$. Sexually transmitted diseases in homosexual men. Am J Public Health 1981;71:989-90.

4. Bell AP, Weinberg MS. Homosexualities: a study of diversity among men and women. Melbourne: Macmillan, 1978.

5. Hart G. Sexual maladjustment and disease: an introduction to modern venereology. Chicago: Nelson Hall, 1977.

6. Suhonen $\mathbf{R}$, Wallenius $J$, Haukka $K$, Elo $O$, Lassus $A$. Syphilis, homosexuality and legislation. Dermatologica 1976; 152:363-6. 